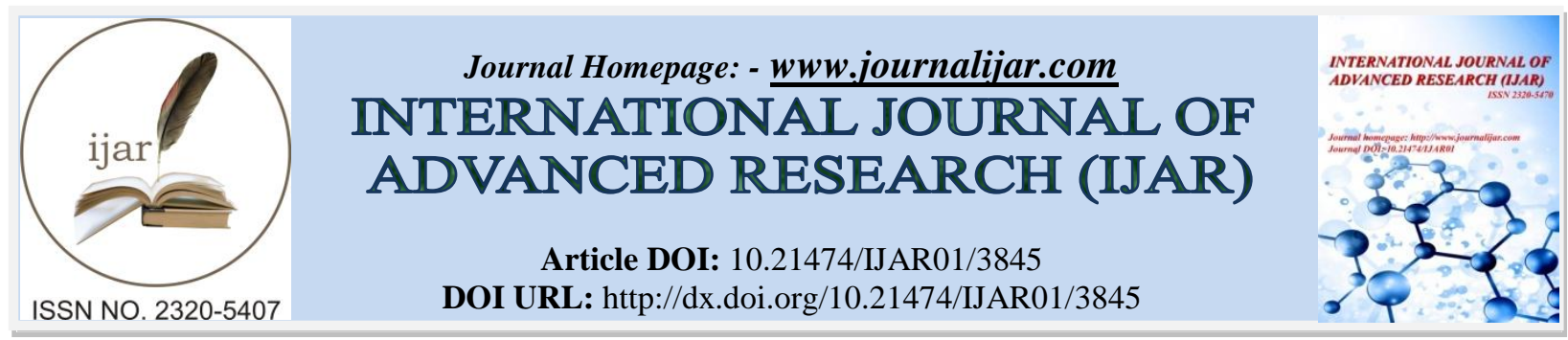

RESEARCH ARTICLE

\title{
EPIDEMIOLOGICAL STUDIES ON SOME BACTERIA CAUSE ABORTION TO SHEEP AND GOATS IN SULAYMANI GOVERNORATE, KURDISTAN, IRAQ.
}

\author{
Sabiha Sharif salih.
}

\section{Manuscript Info}

Manuscript History

Received: 03 February 2017

Final Accepted: 01 March 2017

Published: April 2017

Key words:-

Brucella abortus, Salmonella abortus

Toxoplasma_gondii, in aborted Sheep and got, Antibiotic resistant.

\begin{abstract}
The aim of this study was the main reason cased abortion in Sheep and goats, determination antimicrobial activity; seventy samples were taken from infection Sheep and got suffering from abortion on privately owned farms in some village in Sulaymani city, Iraq. Fore detection the resent of abortion in (Sheep and got) because there are many cases suffering from abortion. Also this Study was done for determined Brucella abortus, and all samples were tested for Brucella, toxoplasma and salmonella abortus, so that all isolated were identified through cultural, morphological and biochemical examination, in addition to API20Esystem. (40) Samples were isolated from (Sheep and got) positive for Brucella abortus, and five sample was positive for Toxoplasma Susceptibility test To eleven antimicrobials were performed for all isolates.. The isolates were grouped to five antibigram The B. abortus isolates were resistant $100 \%$ to Ak .Chl, Tri, $20 \%$ toCip,Cef Nit, 40\%toAmp,Str60\% to Gm ,Rf $80 \%$ to Tet that result Resist to more than two antibiotics.
\end{abstract}

Copy Right, IJAR, 2017,. All rights reserved.

\section{Introduction:-}

Brucellosis also known as "undulant fever", "Mediterranean fever" or "Malta fever" is a zoonosis and the infection (Al-Ani et al. 2004 Anon 2001.) is almost invariably transmitted by direct or indirect contact with infected animals or products. (Al Dahouk et al., 2003; Young, 1995)It affects people of all Ages groups and sex. Although there have been great progress in controlling the disease in many countries, there still remain regions where the infection persists in domestic animals and, consequently, transmission to

The human (shekespeare m2009., ocholi r.a., kwaga j.k.p.at el 2005)population frequently occurs. Brucellosis is an infectious disease of animals that is caused by a number of host-adapted species of the Gram negative intra cellular bacteria of the genus Brucella. The disease is characterized by abortion (atlas, r.m., et al1995., goden, b., e., a m. athamna, 2005, refai m 2002), retained placenta, orchitis and epididymitis. It is a worldwide zoonotic disease that is recognized as a major cause of heavy economic losses to the livestock industry, and also poses serious human health hazards. While the disease has been eradicated in most industrialized regions, its occurrence is increasing in developing countries. Brucellosis is widespread in Africa, Asia

Latin America and South Europe where it remains one of the most Important zoonotic diseases(minas a 2006, refai m2002) 
AlsoBrucellosis is endemic in Slumanya city (in Iraqi and, as elsewhere, causes severe economic losses to livestock farmers and ranchers, and is a serious risk to human health Studies in various parts of the country indicate that the disease is widespread among cattle populations particularly in ranches, bakrajow, kolawasy, kany goma, hanaran farms. In these locations, the prevalence of the disease in Sheep ranges between 3o \% and while in some field in( klawasy, bakrajow ) 50\% so that in same Village in Sulaymani city has shown that common in cattle, sheep and goats, although the causes of such abortions have not always been investigated in detail in the laboratory. Brucellosis in sheep and goats is usually caused by B.melitensis. Infection with B. abortus is rare, so that some samples IGg,IgM for Toxoplasma positive although the association of $\boldsymbol{B}$. abortus with abortion in sheep has be the aim of this paper.

\section{Materials and Methods:-}

Local bacterial isolates:-

Forty isolated of Brucella abortus were isolated taken from blood Sheep and goats in Sulaymani city, Iraq during April to May(2015-2016) all samples were tested cultural depending on, Morphological and biochemical analysis according to (Andrews and Hammack, 2000) APIE system performed and Serology can be used for a presumptive diagnosis of Brucella abortus Salmonella thyphi, and toxoplasma Brucella abortus .can be isolate on variety of plain media .or selective media such as Tryptone soya agar, Columbia agar, Brucella agar, in reach meant media (Brain heart infusion) was used( Alton G.Gat.el1988) The culture samples collected from each aborting ewe are shown in Table 1. It was not possible to isolate culture from aborted fetus and placentas as these materials had been discarded or buried by the time the investigation was conducted. Primary isolation of Brucella was made by culturing the samples on Colombia agar, Brucella agar prepared ( Ouahrani -Bettache S.at.el1996) supplemented with 5\%Horse serum, , and all ready-mixed antibiotic supplement Vancomycin, $20 \mu \mathrm{g}$ at the following amounts per $\mathrm{ml}$ of media:. The inoculated plates were incubated aerobically at $37^{\circ} \mathrm{C}$ in an atmosphere of $5 \%$ to $10 \% \mathrm{CO}$, and examined after three to five days for Brucella-like colonies. The plates were discarded if no growth was evident after seven to ten days of incubation isolates bacteria in the blood of Sheep and goats were performed according to Goden et al. (2005) the Isolates obtained from culture samples were identified as Described by (Alton et a1998)

\section{Antibiotics used:-}

The susceptibility of the (40) samples of B. abortus isolates against (Amikacin .AK Ampicillin ,Amp Cephalosporin Cef,Cefotaxim, Ciprofloxacin Cip,Chloram phenicol Chl, Gentamycin Gm., Rifampicin Rif, Streptomycin Str, Tetracycline Tet, Nitrofurantoin ,Nit and Trimethoprim Tri) was using disk diffusion method (Atlas et al1995)

\section{Results:-}

Out70 samples only (40)were gave positive for Brucella_abortus , 5 samples were positive for Toxoplasma_gondii all samples were taken from blood Sheep and goats in Sulaymani city, Iraq during April to May(2015-2016) suffering from abortion so that all isolated were identified through cultural, morphological and biochemical examination, The API 20E system was performed to support the identification process, The inoculated plates were incubated at $37^{\circ} \mathrm{Cin}$ the presence 5\%-10\% CO2 (candle jar) for up to 7-10 day. After the incubation, the suspected colonies were examined for Brucella sp. Brucella-suspected colonies were characterized by the morphology, negative Gram stain, oxidase, catalase positive, and urease production, nitrate reduction, the samples(Brucella abortus )were grown on Tryptone soya agar, Columbia agar, Brucella agar Mac Conkey agar.In Addition, apart from a rapid slide agglutination test for Brucella abortus Rose bangle test were done for all sample. Then IGg, Igm for Salmonella abortus, and toxplasma were done. Table(1)show that's IGg ,Igm for salmonella abortus negative ,but only sample (1, 16,)were IGg,Igm positive for Toxoplasma gondii but sample (1,5,12,16,23)were positive Antibody for(Igm) Toxoplasma_gondii so( that all 40 sample (excepted) $(1,5,12,16,23)$ positive for Brucella abortus According all tested Which were shown in table(1) such as culture and serological test (Rose bangle) Among 40samples Susceptibility was tested to antimicrobials Resistant were performed for all isolates. That were shown in table(2)The isolates were grouped To five anti-bigram The $\boldsymbol{B}$. abortus isolates were resistant 100\%to Ak .Chl, Tri, $20 \%$ toCip,Cef Nit, $40 \%$ toAmp,Str $60 \%$ to $\mathrm{Gm}$,Rf $80 \%$ to Tet. 
Table 1:- Diagnose of blood, serum of sheep and goat.

\begin{tabular}{|c|c|c|c|c|c|}
\hline No & $\begin{array}{ll}\text { Culture } & \text { for } \\
\text { Brucella } & \\
\text { abortus } & \end{array}$ & $\begin{array}{ll}\text { Culture } & \text { for } \\
\text { Salmonella } & \\
\text { abortus } & \end{array}$ & $\begin{array}{l}\text { Agglutination for } \\
\text { Brucella abourtus } \\
\text { (rose bangle test) }\end{array}$ & $\begin{array}{ll}\text { IGg,Igm } & \text { for } \\
\text { Salmonella } & \\
\text { abortus } & \end{array}$ & $\begin{array}{l}\text { Toxoplasma IGg } \\
\text {,Igm }\end{array}$ \\
\hline 1 & Negative & Negative & Negative & Negative & IGg, Igm \\
\hline 2 & + & Negative & Positive & Negative & Negative \\
\hline 3 & + & Negative & Positive & Negative & Negative \\
\hline 4 & + & Negative & Positive & Negative & Negative \\
\hline 5 & negative & Negative & Negative & Negative & IGg \\
\hline 6 & + & Negative & Positive & Negative & Negative \\
\hline 7 & + & Negative & Positive & Negative & Negative \\
\hline 8 & + & Negative & Positive & Negative & Negative \\
\hline 9 & + & Negative & Positive & Negative & Negative \\
\hline 10 & + & Negative & Positive & Negative & Negative \\
\hline 11 & + & Negative & Positive & Negative & Negative \\
\hline 12 & Negative & Negative & Negative & Negative & IGg \\
\hline 13 & + & Negative & Positive & Negative & Negative \\
\hline 14 & + & Negative & Positive & Negative & Negative \\
\hline 15 & + & Negative & Positive & Negative & Negative \\
\hline 16 & Negative & Negative & Negative & Negative & IGg, Igm \\
\hline 17 & + & Negative & Positive & Negative & Negative \\
\hline 18 & + & Negative & Positive & Negative & Negative \\
\hline 19 & + & Negative & Positive & Negative & Negative \\
\hline 20 & + & Negative & Positive & Negative & Negative \\
\hline 21 & + & Negative & Positive & Negative & Negative \\
\hline 22 & + & Negative & Positive & Negative & Negative \\
\hline 23 & Negative & Negative & Negative & Negative & IGg \\
\hline 24 & + & Negative & Positive & Negative & Negative \\
\hline 25 & + & Negative & Positive & Negative & Negative \\
\hline 26 & + & Negative & Positive & Negative & Negative \\
\hline 27 & + & Negative & Positive & Negative & Negative \\
\hline 34 & + & Negative & Positive & Negative & Negative \\
\hline 35 & + & Negative & Positive & Negative & Negative \\
\hline 36 & + & Negative & Positive & Negative & Negative \\
\hline 37 & + & Negative & Positive & Negative & Negative \\
\hline 38 & + & Negative & Positive & Negative & Negative \\
\hline 39 & + & Negative & Positive & Negative & Negative \\
\hline 40 & + & Negative & Positive & Negative & Negative \\
\hline 41 & + & Negative & Positive & Negative & Negative \\
\hline 42 & + & Negative & Positive & Negative & Negative \\
\hline 43 & + & Negative & Positive & Negative & Negative \\
\hline 44 & + & Negative & Positive & Negative & Negative \\
\hline 45 & + & Negative & Positive & Negative & Negative \\
\hline
\end{tabular}

Table 2:- Antibiogram of B. abourtus isolated from blood sheep, goat seafaring from abourtion.

\begin{tabular}{|l|l|l|l|l|l|l|l|l|l|l|l|l|}
\hline $\mathrm{n}$ & $\begin{array}{l}\text { Antibiogram } \\
\text { groups of_Brucella_abortus }\end{array}$ & Nit & Ak & Chl & Amp & Cef & Rif & Gm & Str & Cip & Tet & Tri \\
\hline 1 & \multicolumn{1}{|c|}{$3,4,6,7,8,9,10,11$} & R & R & R & S & R & S & S & S & R & S & R \\
\hline 2 & $14,15,17,18,21,24,25,26$ & S & R & R & R & R & R & S & R & R & R & R \\
\hline 3 & $27,29,30,31,32,33,35,37$ & R & R & R & S & S & S & S & S & R & S & R \\
\hline 4 & $1,12,1316,19,20,22,23$ & R & R & R & R & R & R & R & R & S & S & R \\
\hline 5 & $2,5,28,34,36,38,39,40$, & R & R & R & R & R & S & R & R & R & S & R \\
\hline
\end{tabular}




\section{Discussions:-}

With the great expansion of livestock industry, Brucella spp. has emerged as a problem of economic concern to all phases of the industry from production to marketing to consumer health signify can't, to clinicians, veterinarians and to thin contact persons due to emergence of multiple drug resistance and due to the fact that intracellular of the organism limits the effect of antibiotics In the present study, Brucella isolates were

Found variably sensitivity to the tested antibiotics. Higher percentages of sensitivity was observed to tetracycline, Which shown in(table2)so that this results similar was obtained by( Hall et al. (1970), who reported treatment of Brucella spp.in (B. canis and B.abortus) infection in mice and guinea pig In the present study,Rifampicin were observed to be moderatly effective. Similar results were obtained in (table)by Bodur et al. (2003), effective. Baykam et al. (2004) reported that Rifampicin is more effective against B. abortus than B. melitensis. In contrast to present study. According to the present findings tetracycline streptomycin ,Rifadin they could be useful to the clinician and veterinary To prevent the further progress of disease and further development of complications in infected human patients and animals by selecting appropriate antibiotics. But, it is also essential to remember that from the public health point of view, prolonged treatment of infected domestic animals with a high dosage of antibiotics cannot be undertaken due to the appearance of in the human food chain, which interferes with the production of milk products. Moreover, as Brucella is facultative intracellular bacteria, relapses after treatment usually occur. Therefore, efforts should be directed at prevention or eradication of brucellosis.

The reason for conducting this research was to determine if the abortion in sheep in villages around Sulaimaniya city was caused by Brucella abortus. This research was conducted on samples that were collected from 70 sheep and got. The tests were mainly conducted to detect Brucella abortus as a cause of abortion in sheep. In addition, we also did some other tests separately on the same samples to determine if the sheep have Salmonella abortus or Toxoplasma was show in table2. Because in some cases Salmonella abortus and Toxoplasma can also be a cause of abortion in sheep. In conclusion, we determined that the abortion in the sheep, goat were mainly caused by Brucella abortus(. We also determined that given small doses of certain antibiotics and plant medicine is really important to maintain the sheep good health. Additionally, we also observed that most of the sheep that we conducted the research on were not vaccinated against Brucella abortus. Also, their living environment was not healthy and this might have been the cause of their infection in the first place the percentage of infected for Brucella abortus were caused abortion in this research were $57.1 \%$, but the infection by toxoplasma gondii $7.1 \%$. so there are no any case infected by Salmonella abourts.

\section{References:-}

1. Andrews, w.h. and t. hammack, 2000.bacteriological analytical manual. fda, us food and drug administration-

2. atlas, r.m., a.e. brown and 1.c. parks, 1995.laboratory manual experimental microbiology. mosby-year book inc., st louis.

3. Alton G.G., Jones L.M., Angus R.D. \& Verger J.M. (1988). -Techniques for the brucellosis laboratory. Institut National de la Recherche Agronomique, Paris, 63-129.

4. Goden, b., e. touitou, e. rubenstein, a. athamna and m. athamna, 2005. a new approach for atreatment of deep skin infection by an ethosomal antibiotic preparation: an in vivo study. j. antimicrob. chemother., 55: 989-994.

5. (Al Dahouk et al., 2003; Young, 1995) Al Dahouk, S., Tomaso, H., No“ ckler, K., Neubauer, H. \& Frangoulidis, D. (2003). Laboratory-based diagnosis of brucellosis - a review of the literature. Part II: serological tests for brucellosis. Clin Lab 49, 577-589. Young, E. J. (1995). An overview of human brucellosis. Clin Infect Dis 21, 283-289.

6. Ouahrani-Bettache S., Soubrier M., Liautard J., IS6501-anchored PCR for the detectionand identification of Brucella species and

7. strains, J. Appl. Bacteriol. 81 (1996) 154-160

8. Alani f.k., qaderi n.q., razziq r., al-darraji a.m.:human and animal brucellosis in jordan between 1996-1998: a study. rev sci tech off int epiz 2004, 23, 831-840.

9. $\quad$ shekespeare m. zoonosis.pharmaceutical press.rps publishing, london. 2009.pp:48-92.

10. anon.: brucellosis in sheep and goats (brucellamelitensis). scientific committee on animal health and animal welfare. european commission, 2001

11. Hall WH, Manion RE. In vitro susceptibility of Brucella to various antibiotics. Appl Microbiol. 1970;20:600-604 Alton et a1998

12. Minas a.: control and eradication of brucellosis in small ruminants. small rum res 2006, 62, 101-107. 
13. Baykam n., esener h., ergonul o., eren s., celikbas ak., dokuzoguz b. (2004): in vitro antimicrobial susceptibility of brucella species. int j antimicrob agents; 23: 405-7

14. Bodur h., balaban n., aksaray s., yetener v., akinci e., colpan a. et al. (2003): biotypes and antimicrobial susceptibilities of brucella isolates. scand $j$ infect

15. refai m.: incidence and control of brucellosis in the near east region. vet microbiol 2002, 90, 81-110. 